\title{
Representing the Sensitivity of Convective Cloud Systems to Tropospheric Humidity in General Circulation Models
}

\author{
Anthony D. Del Genio
}

Received: 7 May 2011/Accepted: 8 September 2011/Published online: 30 September 2011

(C) The Author(s) 2011. This article is published with open access at Springerlink.com

\begin{abstract}
Convective cloud variability on many times scales can be viewed as having three major components: a suppressed phase of shallow and congestus clouds, a disturbed phase of deep convective clouds, and a mature phase of transition to stratiform upper-level clouds. Cumulus parameterization development has focused primarily on the second phase until recently. Consequently, many parameterizations are not sufficiently sensitive to variations in tropospheric humidity. This shortcoming may affect global climate model simulations of climate sensitivity to external forcings, the continental diurnal cycle of clouds and precipitation, and intraseasonal precipitation variability. The lack of sensitivity can be traced in part to underestimated entrainment of environmental air into rising convective clouds and insufficient evaporation of rain into the environment. As a result, the parameterizations produce deep convection too easily while stabilizing the environment too quickly to allow the effects of convective mesoscale organization to occur. Recent versions of some models have increased their sensitivity to tropospheric humidity and improved some aspects of their variability, but a parameterization of mesoscale organization is still absent from most models. Evidence about the effect of these uncertainties on climate change projections suggests that climate modelers should make improved simulation of high and convective clouds as high a priority as better representations of low clouds.
\end{abstract}

Keywords Convection $\cdot$ Climate $\cdot$ Humidity $\cdot$ Diurnal cycle $\cdot$ Intraseasonal variability

\section{Introduction}

Spatial variations of insolation and sea surface temperature, and differences in the thermal inertia and albedo of land and ocean surfaces, create energy and water flows between the tropics and subtropics, between warm and cold oceanic regions, and between oceans and

\footnotetext{
A. D. Del Genio $(\bowtie)$

NASA Goddard Institute for Space Studies, 2880 Broadway, New York, NY 10025, USA

e-mail: anthony.d.delgenio@nasa.gov

URL: http://www.giss.nasa.gov/staff/adelgenio.html
} 
continents that have major effects on the planetary energy balance and feedbacks that determine the response of each to climate forcings (e.g., Trenberth et al. 2009; Fasullo 2010). Our understanding of these feedbacks comes primarily from simulations of different climates by general circulation models (GCMs). The energy and water transfers are accomplished by the large-scale atmospheric circulations that GCMs explicitly resolve, but the strength of these circulations and the energy and water that is transported depend crucially on parameterized small-scale processes whose treatment in GCMs is regarded to be highly uncertain.

Perhaps the most important of these parameterization uncertainties is that due to moist convection. Dynamical upward transport by convection removes excess heat from the surface more efficiently than longwave radiation is able to accomplish in the presence of a humid, optically thick boundary layer, and deposits it in the upper troposphere where it is more easily radiated to space, thereby affecting the planetary energy balance. Drying and moistening of the atmosphere by convection regulates the vertical profile of atmospheric water vapor and thus determines how much is transported horizontally. Furthermore, convection influences where clouds form and dissipate, thus affecting the planetary albedo and potentially giving rise to cloud and water vapor feedbacks that determine the global climate sensitivity to anthropogenic forcing.

Mapes et al. (2006) argue that moist convective variability can be understood in terms of three basic convective structures, or "building blocks" (Fig. 1). During suppressed conditions when the boundary layer is capped by a significant inversion and/or the free troposphere above is dry, shallow and midlevel-top ("congestus") convective clouds that heat and moisten the lower troposphere are most common. As the atmosphere humidifies and destabilizes, deep convection is eventually triggered, heating the entire column, while shallow clouds continue to be present. Finally, under the right environmental conditions, individual deep convective cells organize into mesoscale clusters with extensive stratiform rain regions and anvils that primarily heat the upper troposphere through mesoscale updrafts and latent heating but cool the lower troposphere as falling rain evaporates.

This sequence describes the $\sim 12$ - to 24-h lifecycle of individual convective clusters (Houze 2004; Futyan and Del Genio 2007), but Mapes et al. (2006) suggest that longerterm convective variability on time scales of days to several months can be understood by "stretching" the same set of three building blocks. In this view, longer-term periods of suppressed, disturbed, and mature convective conditions have different relative frequencies of occurrence of the three building blocks, thus shifting the convective heating profile downward and upward over time. Mapping of International Satellite Cloud Climatology Project (ISCCP) cloud classification and CloudSat/CALIPSO cloud profile occurrences onto many individual episodes of the Madden-Julian Oscillation (MJO) (Fig. 2) provides strong observational support for this idea (Chen and Del Genio 2009; Tromeur and Rossow 2010; Del Genio et al. 2011a). Morita et al. (2006) present evidence of similar behavior in Tropical Rainfall Measuring Mission (TRMM) microwave and radar rain top heights. Kiladis et al. (2005) show that diabatic heating anomalies regressed against eastwardpropagating intraseasonal outgoing longwave radiation variability show exactly the type of upward-westward tilting heating pattern that is consistent with the stretched building block picture (Fig. 3). They also show that most of the heating can be decomposed into a first baroclinic mode with heating throughout the troposphere that captures the middle deep convective phase and a second baroclinic mode with opposite-signed heating in the upper and lower troposphere that in its opposite phases describes the shallow/congestus and mature stratiform components. A number of simple theories of tropical convectively 
(a)

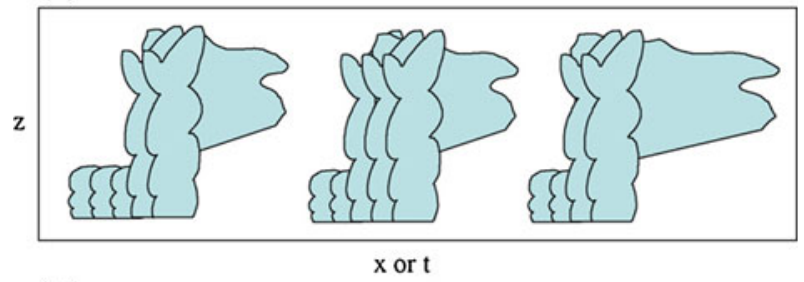

(b)

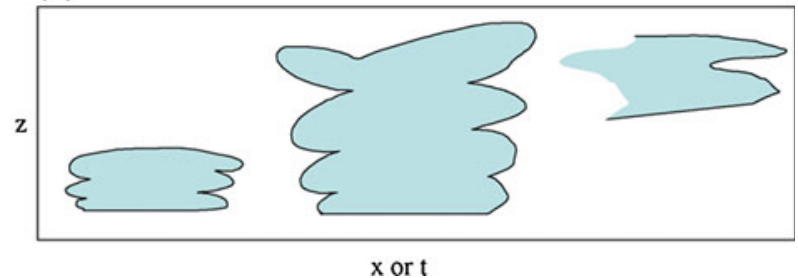

Fig. 1 Schematic illustration of the stretched building block hypothesis. Individual mesoscale convective systems (upper panel) consist of contributions from shallow/congestus clouds, deep convective clouds, and stratiform rain and anvil areas. On longer time scales, large-scale waves modulate environmental conditions so as to change the relative frequency of occurrence of the three building blocks, so that a smoothed, lowpass filtered view of the variability (lower panel) has a structure similar to that of an individual mesoscale convective system. Reprinted from Mapes et al. (2006) with permission from Elsevier

coupled waves invoke this dual baroclinic mode structure (e.g., Mapes 2000; Khouider and Majda 2006; Kuang 2008).

\section{Implications for Cumulus Parameterization and Energy Flows}

Despite decades of model development, cumulus parameterizations still have great difficulty simulating the observed variability of moist convection and its interaction with the general circulation. Viewed from the building block perspective, it is easy to understand why. Much of the history of cumulus parameterization has been devoted to diagnosing individual deep convective events and the heating profiles they produce. Although some cumulus parameterizations represent a spectrum of convective types of different depths (e.g., Arakawa and Schubert 1974; Moorthi and Suarez 1992; Donner 1993), these schemes tend to underestimate shallow and congestus convection, most likely because of design elements and validation approaches more appropriate to deep convection. Other schemes only simulate deep convection (e.g., Emanuel 1991; Zhang and McFarlane 1995), sometimes with an additional scheme for removing instability at midlevels (Hack 1994), thus necessitating a separate shallow convection parameterization. Only in the past decade or so have the latter received significant attention, largely as a result of insights gained from large-eddy simulation (LES) models (e.g., Siebesma et al. 2003). Organization of convection into clusters with mesoscale updrafts and downdrafts has only been attempted in one parameterization to date (Donner 1993).

The unsatisfactory state of modern cumulus parameterization was brought into the harsh light of day by Derbyshire et al. (2004). A set of idealized case studies with a thermodynamic structure unstable to deep convection was simulated by several cloud-resolving models (CRMs) with free troposphere humidities ranging from 25 to $90 \%$. The CRMs 

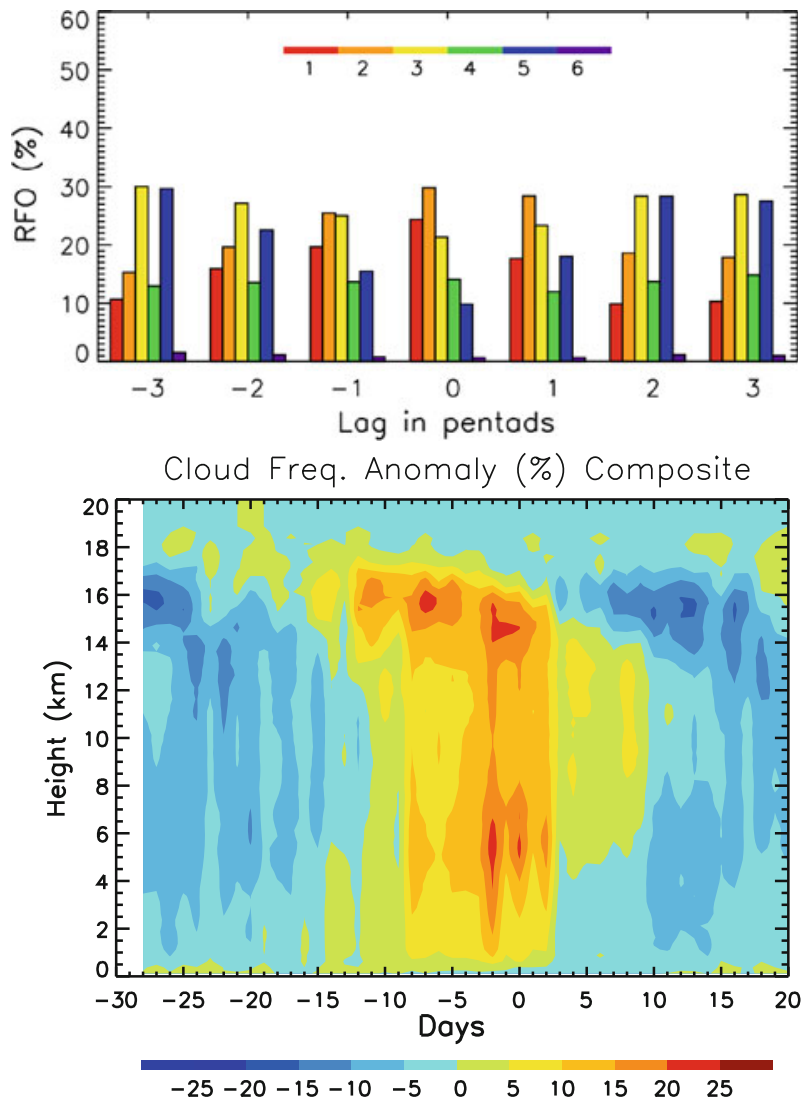

(\%)

Fig. 2 Composite cloud frequency of occurrence as a function of MJO phase (expressed as lag in pentads relative to the peak). Upper panel ISCCP cloud regimes from k-means clustering analysis. Red deep convective, orange stratiform anvil, yellow congestus/disorganized convection, green isolated cirrus, blue shallow cumulus, violet stratocumulus. From Chen and Del Genio (2009). Lower panel CloudSat/CALIPSO GEOPROF-LIDAR cloud mask anomalies. From Del Genio et al. (2011a)

simulated shallow convection for the driest case and made a gradual transition to deep convection as tropospheric humidity increased. A number of single column models (SCMs) constructed from the parameterizations of GCMs were found to be much less sensitive to tropospheric humidity, some still producing deep convection in even the driest environment. This sensitivity of moist convection to environmental humidity has been indirectly observed as a sharp increase in precipitation with column water vapor at values of 40-55 mm (Bretherton et al. 2004). Holloway and Neelin (2009) show a similar sensitivity in soundings taken at the Department of Energy Atmospheric Radiation Measurement (ARM) Program site at Nauru Island and also show that the variation in column water is dominated by changes in the mid-troposphere (Fig. 4). Cloud radar profiles at Nauru and CloudSat/CALIPSO radar/lidar profiles demonstrate that convective penetration depth is limited in drier environments (Jensen and Del Genio 2006; Del Genio et al. 2011a). These results have been interpreted to indicate that the turbulent entrainment of drier air into cloudy convective updrafts is greatly underestimated by GCMs. 
Fig. 3 a Observed diabatic heating anomaly profiles regressed against $\mathrm{MJO}$-filtered outgoing longwave radiation during TOGA-COARE as a function of time relative to the MJO peak. b First baroclinic mode of the heating. c Second baroclinic mode of the heating. Dark (light) shading represent positive (negative) anomalies; the contour interval is $0.5^{\circ} \mathrm{C} \mathrm{day}^{-1}$. From Kiladis et al. (2005) (c) Copyright 2005 AMS)

\section{(a) Q1 Total}

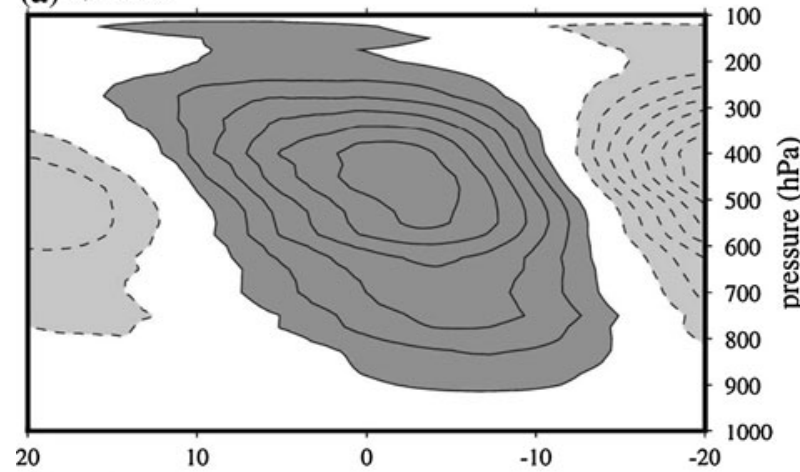

(b) Q1 First Mode $(49 \mathrm{~m} / \mathrm{s})$

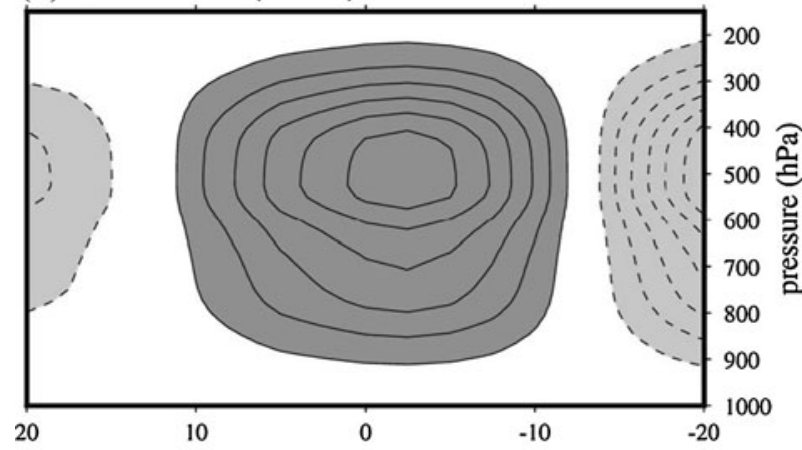

(c) Q1 Second Mode $(23 \mathrm{~m} / \mathrm{s})$

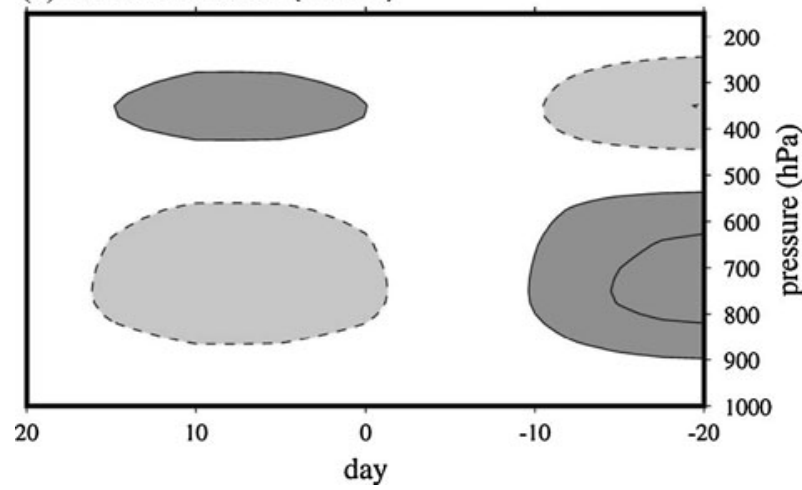

The relative insensitivity of GCM cumulus parameterizations to tropospheric humidity has potentially important consequences for modeling of energy transfers within the climate system. Sanderson et al. (2010), for example, analyzed a perturbed parameter ensemble of thousands of simulations of one GCM with different values for various free parameters in each ensemble member for current and doubled $\mathrm{CO}_{2}$ forcing. They showed that the cumulus parameterization's entrainment coefficient had the greatest effect on model feedbacks and climate sensitivity (Fig. 5), including a large effect on the water vapor feedback via changes in the vertical profile of water vapor-a result not previously demonstrated in any GCM. This illustrates the mutual relationship between convection and 


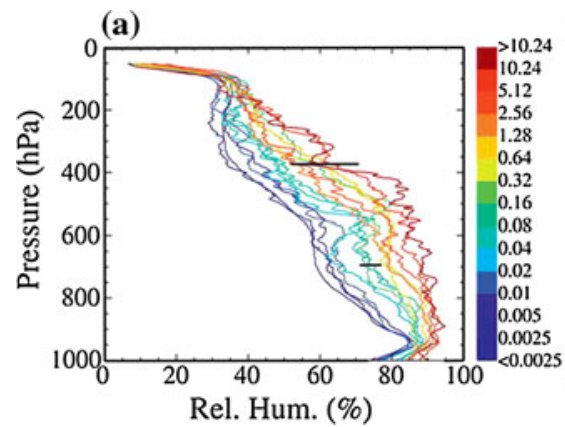

(b)

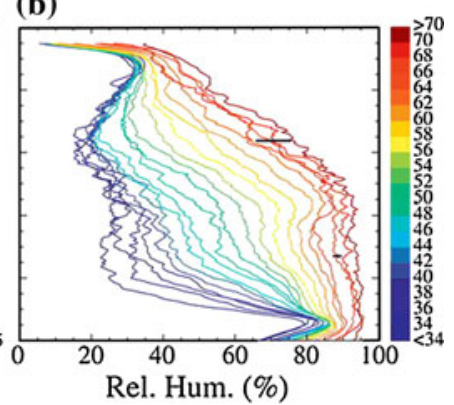

Fig. 4 Composite relative humidity profiles from soundings at the DOE ARM Nauru Island site binned by 1 -h mean precipitation rate in $\mathrm{mm} \mathrm{h}^{-1}$ (left) and by column water vapor in $\mathrm{mm}$ (right). The horizontal bars indicate the limits of the maximum and a typical standard error. From Holloway and Neelin (2009) (C) Copyright 2009 AMS)

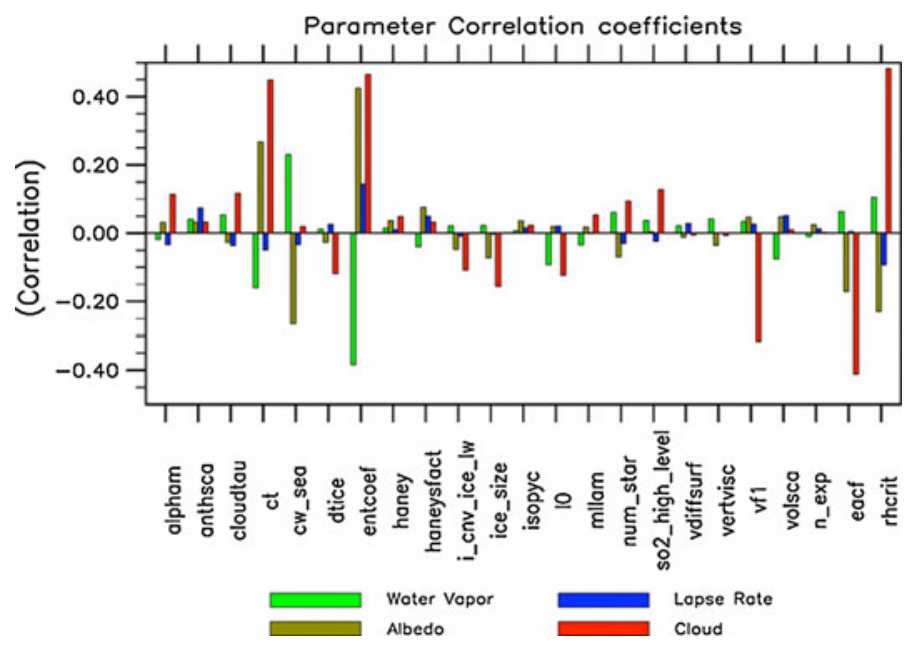

Fig. 5 Correlation coefficients between values of free parameters in the climateprediction.net perturbed parameter GCM ensemble and various global mean feedbacks derived from doubled $\mathrm{CO}_{2}$ simulations with each ensemble member. The parameter "entcoef" is the convective entrainment coefficient. From Sanderson et al. (2010). Reprinted with permission of Springer

humidity: the depth of convection depends on how humid the surrounding environment is, but the detrainment of saturated air from convective clouds and the evaporation of falling convective rain in turn moisten the environment and thus control the humidity profile.

The effect of entrainment on the transition from shallow to deep convection is important for several aspects of current climate variability as well. For example, the diurnal cycle of continental precipitation exhibits peak rainfall in late afternoon or early evening in TRMM Precipitation Radar data (Hirose et al. 2008; Fig. 6), despite the fact that surface temperature and turbulent fluxes peak near noon. In some cases, this reflects geographic effects or propagation of systems to remote locations. In many situations, though, the atmosphere is simply unstable to deep convection by late morning but does not develop precipitating convection until hours later because entrainment of dry air limits convective penetration 

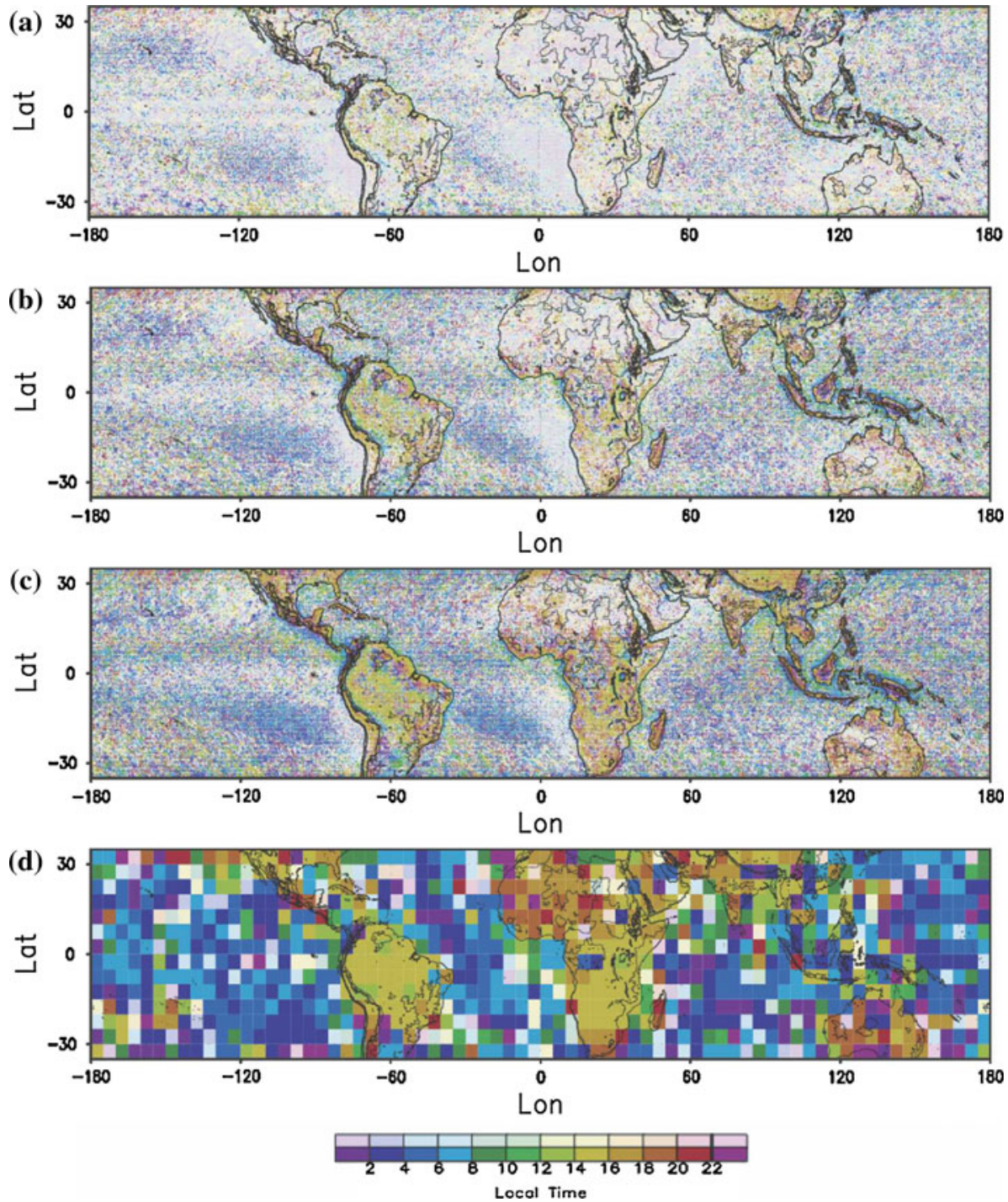

Fig. 6 Local time of maximum rainfall in TRMM Precipitation Radar data at $0.2^{\circ}$ resolution for a 1998 , b 1998-2000, and c 1998-2005, and d at $5^{\circ}$ resolution for 1998-2005. From Hirose et al. (2008) (c) Copyright 2008 AMS)

(Del Genio and Wu 2010; Zhang and Klein 2010). Guichard et al. (2004) and Dai (2006) showed that cumulus parameterizations uniformly simulate continental precipitation that peaks near noon, hours earlier than observed.

This error has potentially serious implications for the ability of GCMs to simulate the energy and water cycles. Convective clusters have large negative shortwave cloud forcing because of their extensive optically thick anvils. The shortwave forcing will be much stronger if it occurs at noon than if it occurs in late afternoon, because of the decrease in insolation over the course of the afternoon. Thus, we might expect the IPCC AR4 GCMs to 
have negative biases in absorbed sunlight over the continents. In fact, if anything, the opposite is true (Trenberth and Fasullo 2010), indicating that the GCMs' diurnal cycle errors are being overcompensated by other serious errors in model clouds. This example illustrates why monthly mean geographical distributions of climate parameters are poor indicators of model performance. The diurnal phase error also has ramifications for the surface water balance-rainfall near noon is more likely to evaporate rather than infiltrate into the soil compared with similar rainfall occurring in late afternoon. Do current GCMs dry out their surfaces too easily because of cumulus parameterization deficiencies, and might this affect projections of increasing drought in a warmer climate?

The relationship between convection and tropospheric humidity also appears to affect the MJO, the most important source of intraseasonal variability in weather in the Indian Ocean, Maritime Continent, and West Pacific regions of the tropics (Madden and Julian 1971). The MJO, a slowly eastward-propagating $\left(\sim 5 \mathrm{~m} \mathrm{~s}^{-1}\right)$ envelope of zonal wavenumber $\sim 1-3$ that modulates the occurrence of precipitating deep convection, is distinct from other types of large-scale equatorial wave modes whose existence is predicted by simple shallow water theory (Wheeler and Kiladis 1999).

General circulation models have historically had great difficulty simulating the amplitude, phase speed, and propagation direction of the MJO (Lin et al. 2006). In part, this is due to the lack of a general consensus on the processes that drive the MJO. Some of the most promising ideas focus on the interaction between convection and tropospheric moisture (Bladé and Hartmann 1993; Hu and Randall 1994; Kemball-Cook and Weare 2001; Stephens et al. 2004; Benedict and Randall 2007). During the dry suppressed phase of the MJO, entrainment limits convective penetration depth, but the resulting shallow cumulus clouds moisten the atmosphere at the level at which they detrain, and also below via rain evaporation. This allows later convective events to rise through a more humid atmosphere and thus penetrate somewhat higher, further "recharging" tropospheric moisture, until the column is sufficiently humid to trigger the disturbed MJO phase. Eventually, deep convection organizes and "discharges" the built-up moisture through precipitation and compensating subsidence drying, returning the atmosphere to the suppressed MJO phase. The ISCCP and CloudSat/CALIPSO composites (Fig. 2) demonstrate that this gradual shift from more frequent shallow clouds to predominantly deep clouds does indeed occur in advance of the peak of the MJO, although by itself this does not prove causality. Nonetheless, it seems more than a coincidence that GCMs whose cumulus parameterizations are insensitive to tropospheric humidity poorly represent this phenomenon.

The MJO produces extended rainy and dry periods of several weeks duration and is thus of great practical importance for countries adjacent to the tropical Indian and West Pacific Oceans. It can also have remote impacts on midlatitude weather (Weickmann et al. 1985). This does not explain the unusual current level of research interest in the MJO, however. Instead, the prevailing view is that the MJO encapsulates much of our ignorance about cumulus parameterization in general. It leads us to question whether aspects of a changing climate and energy balance that depend on how convection interacts with the general circulation, or on how convection redistributes moisture vertically and regulates cloud altitude, are being predicted accurately by the current generation of climate models.

\section{Parameterizing Entrainment in General Circulation Models}

There are clear historical reasons for the apparent underprediction of entrainment by GCMs. Perhaps the most obvious requirement for a cumulus parameterization is that it 
produces deep convective clouds that often reach the tropopause, as commonly observed. Moist static energy in the tropics typically decreases to a mid-troposphere minimum and then increases upward to a tropopause value close to its surface value. Thus, air rising from the boundary layer undiluted by environmental air would lose buoyancy near the tropopause (Riehl and Malkus 1958). Cumulus parameterizations have thus usually assumed that a fraction of the upward mass flux represents protected cloud cores that do not interact with the environment (e.g., Arakawa and Schubert 1974). Warner (1970) showed that it was not possible to simultaneously predict the cloud top height of shallow cumuli (which implied nearly undilute ascent) and their subadiabatic liquid water content and liquid water variability (which implied substantial entrainment), but the "Warner paradox" did not affect parameterization development for decades.

The first acknowledgement by the GCM community that something was amiss in its entrainment assumptions was the study of Tokioka et al. (1988), who showed that, by implementing a non-zero minimum entrainment rate in the Arakawa-Schubert scheme, it was possible to produce an MJO-like disturbance in a GCM. In recent years, CRM studies that diagnosed entrainment rate from the rate of decrease with height of an otherwise conserved quantity (such as moist static energy or a passive tracer) have found that, in typical deep convective environments, undilute plumes do not exist (Khairoutdinov and Randall 2006; Kuang and Bretherton 2006; Romps and Kuang 2010a). Instead, the ability of deep convective parcels to reach the tropopause while entraining is due to overshoot beyond the level of neutral buoyancy combined with the enhancement of the parcel's kinetic energy by the release of the latent heat of fusion (Romps and Kuang 2010a). Even shallow cumuli appear to have a negligible probability of parcels rising to cloud top with no entrainment (Romps and Kuang 2010b).

Early cumulus parameterizations that calculated only the cumulus mass flux assumed that ascent terminated at the level of neutral buoyancy. More recent GCMs now include a diagnostic equation for convective updraft speed (Donner 1993; Jakob and Siebesma 2003; Del Genio et al. 2007) and thus account for overshoot. The issue then becomes how to parameterize the entrainment rate (which also affects the updraft speed). Most cumulus parameterizations in use in GCMs today assume either a single laterally entraining bulk plume (e.g., Gregory and Rowntree 1990) or a spectrum of laterally entraining plumes (e.g., Arakawa and Schubert 1974) with constant entrainment rate or a fixed inverse-height dependence (e.g., Jakob and Siebesma 2003; Neale et al. 2008).

The lateral entrainment concept has been questioned due to observations that suggest that mixing in clouds is primarily due to air that enters through cloud top and forms subcloud-scale penetrative downdrafts (e.g., Paluch 1979). This led to the development of episodic "buoyancy-sorting" parameterizations that assumed a variety of mixtures of cloud and environment air that would ascend or descend to their levels of vanishing buoyancy (e.g., Emanuel 1991). Lagrangian particle tracking of shallow cumulus in LES models has raised doubts about the interpretation of the Paluch data and suggested that most entrainment is in fact lateral (Heus et al. 2008). Several LES studies suggest that the observed properties of shallow cumulus can be explained, and the Warner paradox resolved, by an "intermittent entraining thermal" approach. In this view, many individual subcloud-scale elements rising from the boundary layer experience different entrainment histories; this naturally explains the observed cloud top, the subadiabatic liquid water, and its variability. There is disagreement, however, about whether the entrainment that different parcels experience is best described by applying a deterministic entrainment rate to parcels with different initial properties due to boundary-layer heterogeneity (Neggers et al. 

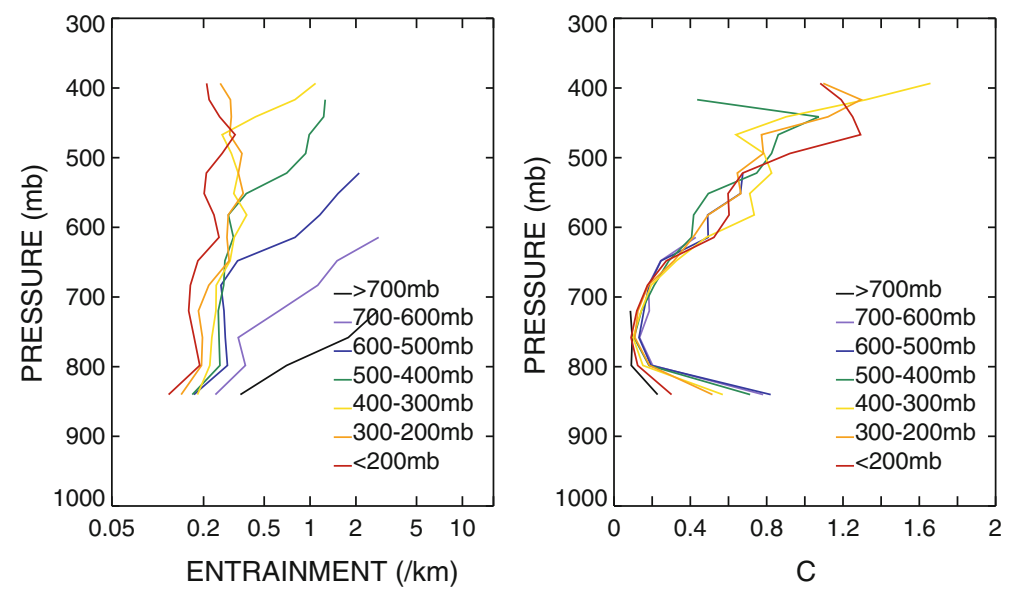

Fig. 7 Left CRM-inferred entrainment rate versus height for convective events penetrating to different pressure levels. Right inferred values of free parameter $C$ in the Gregory (2001) entrainment parameterization for the convective events in the left panel. From Del Genio and Wu (2010)

2002) or by assuming stochastic entrainment with no boundary-layer variability (Romps and Kuang 2010b).

The stochastic approach may be a promising path for future parameterization development, especially given the variety of individual convective cloud depths observed by CloudSat/CALIPSO for a given amount of water vapor (Del Genio et al. 2011a). Until such parameterizations are available, however, the simple laterally entraining bulk plume provides a useful (albeit impressionist) way to capture the sensitivity of convection depth to tropospheric humidity on GCM space and time scales. The simplest response to the study of Derbyshire et al. (2004) is to just increase the specified entrainment rate assumed in a given GCM. This is unsatisfying, however, as parameterization development must ultimately move toward physically based approaches that can respond to variations in atmospheric state and have predictive capability for climate change.

Several interactive approaches to entrainment parameterization have in fact been proposed, and CRMs offer a platform for testing them. Del Genio and Wu (2010) diagnosed entrainment rates from the upward decrease in frozen moist static energy in a CRM simulation of daytime convection development over land, finding entrainment rates much larger than those typically assumed in GCMs and a decrease in the entrainment rate as convection deepened (Fig. 7, left), a behavior also inferred in previous studies (Grabowski et al. 2006; Khairoutdinov and Randall 2006; Kuang and Bretherton 2006). Del Genio and $\mathrm{Wu}$ compared the predictions of three proposed entrainment parameterizations to these results. A scheme proposed by Gregory (2001) based on a convective turbulence scaling view calculates the entrainment rate as $\varepsilon(z)=C B / w^{2}$, where $B$ is the parcel buoyancy, $w$ the convective updraft speed, and $C$ a free parameter representing the fraction of the buoyant turbulent kinetic energy generation used for entrainment. $\varepsilon, B$, and $w$ can all be diagnosed from the CRM updraft columns and the resulting $C$ calculated. Figure 7 (right) shows that a single profile of $C$ is valid for all types of convection from shallow to deep. Thus, the Gregory scheme may capture something fundamental about the relationship between cloud-scale buoyancy and smaller-scale turbulence via the inertial cascade (Grant and Brown 1999), although the question of what determines the vertical profile of $C$ remains open. 


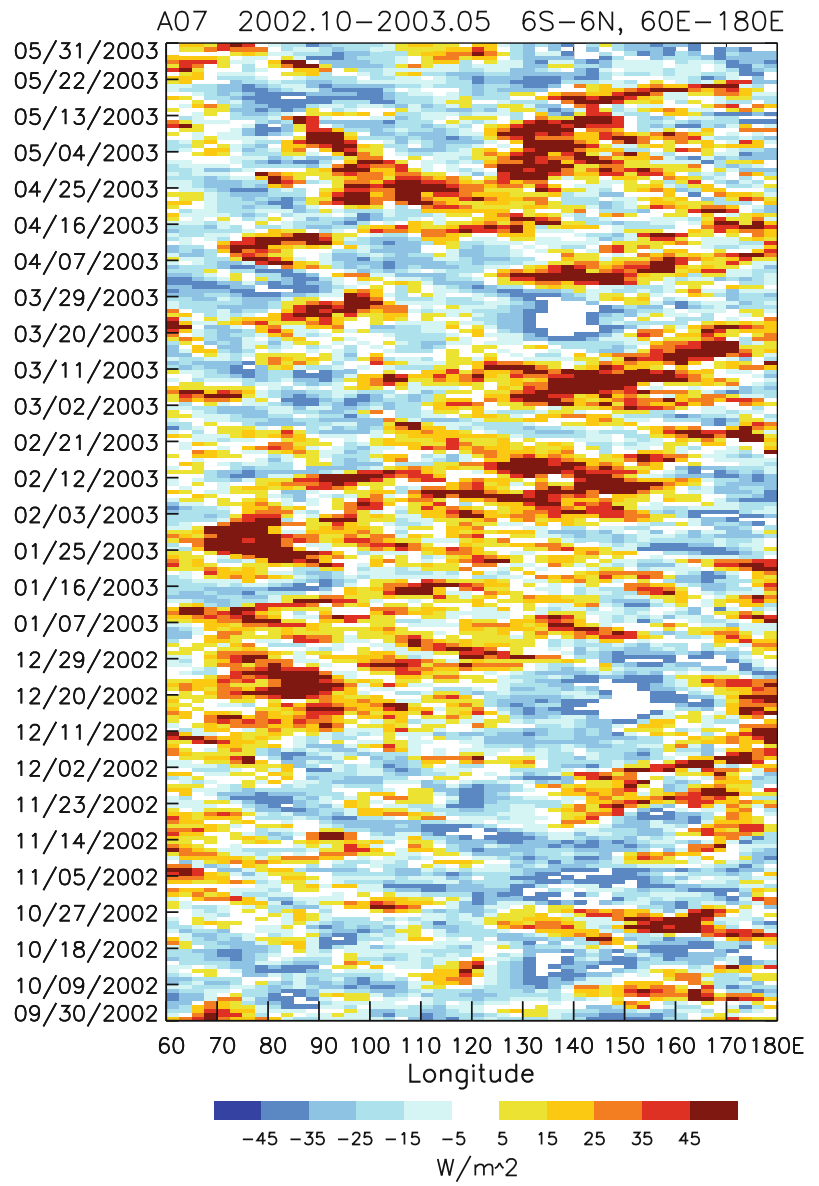

Fig. 8 Hovmöller diagram of outgoing longwave radiation (OLR) anomalies for the equatorial Indian Ocean-Maritime Continent-West Pacific region for an experimental version of the GISS Model E2 GCM that produces MJO-like variability. An example can be seen starting near $60^{\circ} \mathrm{E}$ in late January and reaching the dateline in late February, implying an eastward propagation speed of $\sim 5 \mathrm{~m} \mathrm{~s}^{-1}$. Positive anomalies indicate more high, thick cloud. From Del Genio et al. (2011a)

The GISS Model E2 GCM, which implemented the Gregory scheme with $C=0.3$ and 0.6 for its two convective plumes, does not produce an MJO. However, with the value $C=0.6$ for both plumes, MJO-like variability emerges (Kim et al. 2011a). An even more well-defined MJO occurs when both entrainment and rain evaporation into the environment are increased. An example from a radiatively balanced version of this latter model is shown in Fig. 8 (Del Genio et al. 2011a). Analysis of this model version indicates that unlike the control Model E2, which has a relatively dry mid-troposphere even when column water vapor is high and strong deep convection is occurring, the experimental version has a humid troposphere at all altitudes under heavily raining conditions and a drier upper troposphere when column water vapor is small (Fig. 9). This is consistent with the conclusion of Thayer-Calder and Randall (2009) about why the super-parameterization version of the Community Atmospheric Model simulates the MJO better than the version with a conventional cumulus parameterization. 
Fig. 9 Composite vertical profiles of relative humidity versus precipitation for the tropical Indian Ocean-Maritime Continent-West Pacific region for the GISS Model E2 GCM version that does not produce an MJO (upper), the experimental model version with stronger entrainment and rain evaporation seen in Fig. 8 that does produce MJO-like variability (middle), and the difference between the two (lower). From Del Genio et al. (2011a)

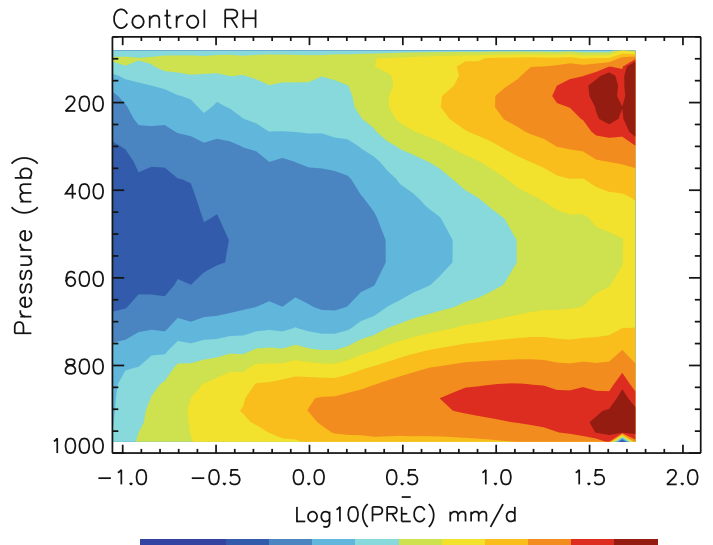

$\begin{array}{lllllllllll}5 & 10 & 20 & 30 & 40 & 50 & 60 & 70 & 80 & 90 & 95\end{array}$

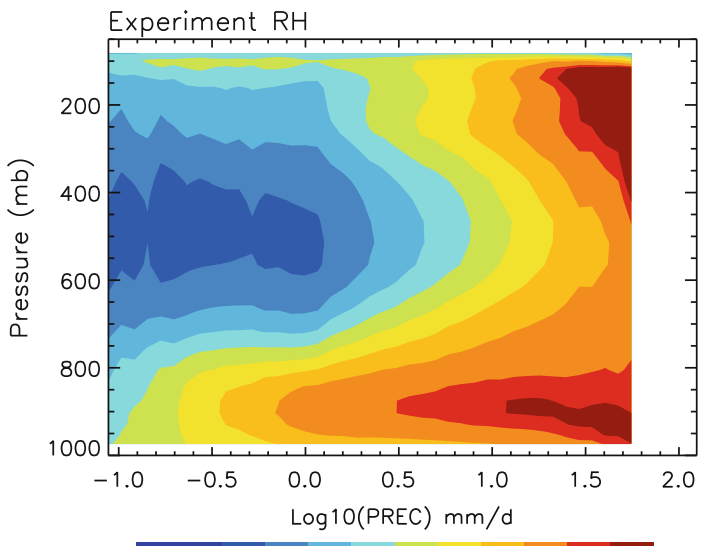

$\begin{array}{lllllllllll}5 & 10 & 20 & 30 & 40 & 50 & 60 & 70 & 80 & 90 & 95\end{array}$

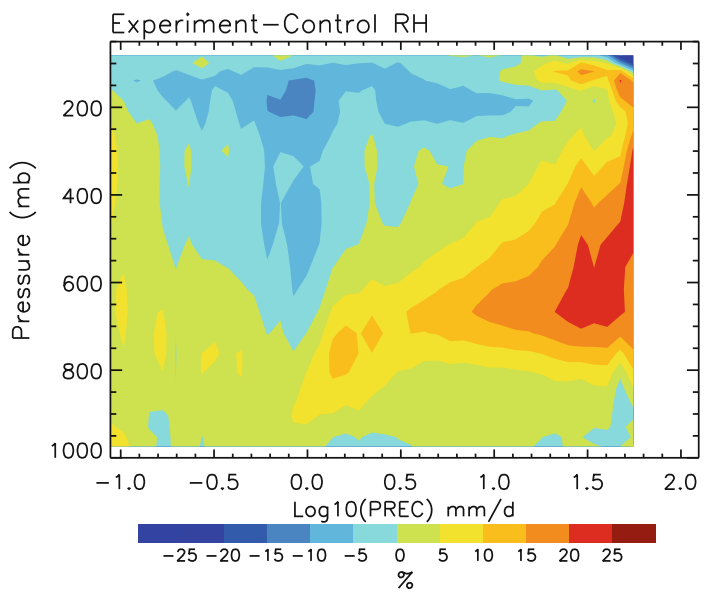

Another possibly relevant factor for GISS Model E2 is that the experimental version shifts the cumulus mass flux and heating peak downward, since stronger entrainment produces lower cloud top heights. This helps produce second baroclinic mode vertical 
heating structure (Fig. 3) that may be missing from the control model version. More shallow convection allows moist static energy imported into the column by large-scale moisture convergence to build up rather than immediately being exported by deep convection. Thus, the experimental model version may have smaller gross moist stability during the shallow-deep transition phase, destabilizing the MJO (Raymond et al. 2009).

The experience with the MJO in GISS Model E2 is consistent with effects that can be produced in many other GCMs by increased entrainment, a stronger trigger for deep convection initiation, or increased rain evaporation (Kim et al. 2009; Hannah and Maloney 2011). Why, then, do so many operational GCMs have dry middle tropospheres and poor MJOs? Kim et al. (2011b) show that physics changes that strengthen the MJO degrade other aspects of the model mean climate, e.g., excessive mean rainfall and intraseasonal rainfall variance. In other words, although a stronger link between convection and moisture increases large-scale variability, by itself it does not focus enough of it into the observed frequencies and wavenumbers. The reason for the MJO-mean state tradeoff appears to be that a parameterization that adequately suppresses convection in dry environments overly limits it in more favorable environments in which larger, more vigorous clouds entrain less. Furthermore, although stronger entrainment produces MJO-like variability in GISS Model E2, it does not by itself shift its noon peak in continental precipitation to later times. What is still missing from the models that might explain this?

\section{The Next Parameterization Frontier: Mesoscale Organization}

Figures 1, 2, and 3 offer a clue to the most glaring remaining deficiency of cumulus parameterizations. We have focused on the first two building blocks of convective systems, deep convective cells that produce first baroclinic mode heating throughout the troposphere and net drying, and shallow/congestus clouds in advance of deep convection that produce second baroclinic mode heating of low levels and moisten the troposphere. The third building block is the upper troposphere stratiform rain region and non-precipitating anvil that occurs as convective cells organize into mesoscale clusters during the mature phase of their lifecycle. Mesoscale updrafts produce condensation heating in the upper troposphere, while melting of falling snow and subsequent evaporation of stratiform rain cool and moisten the lower troposphere (Houze 2004). This produces a second baroclinic mode structure of opposite phase to that which occurs in the shallow/congestus phase.

Many GCMs include detrainment of condensate from their convective updrafts; how much depends on the particle size distribution, fall speeds, and the convective updraft speed (Del Genio et al. 2005). In most GCMs, though, the detrained condensate is treated simply as a stratiform cloud with no dynamics; only one GCM to date includes an estimate of mesoscale updrafts and downdrafts, but coincident with the parent convection (Donner 1993). Thus, we anticipate that most models have at best a very weak and brief second baroclinic mode heating period after deep convection is initiated (e.g., Del Genio et al. 2011b). Several simple models invoke a stratiform heating profile and its interaction with tropospheric humidity as central to the instability driving the MJO (e.g., Khouider and Majda 2006; Kuang 2008).

To move forward in this area, a parameterization must first determine whether convection organizes. Yuter and Houze (1998) discuss the "sustainability" of the environment that allows for continual regeneration of convection, leading to a gradual accumulation of air parcels from weakening convection that form the mesoscale stratiform rain and updraft region. Schumacher and Houze (2006) find that in addition to a warm, humid boundary 
layer that can maintain its thermodynamic state over long time periods, sustainability is enhanced by (1) high tropospheric humidity, which provides a more favorable environment for convection to deepen, and (2) moderate upper-level wind shear, which promotes spreading of condensate from convective updrafts into the stratiform rain region.

The boundary layer is thought to maintain its moist static energy through a quasiequilibrium between the source due to surface turbulent fluxes of latent and sensible heat, and the sink due primarily to convective downdrafts that carry low moist static energy air from the mid-troposphere to the boundary layer (Emanuel et al. 1994). Downdrafts have gradually been introduced into cumulus parameterizations over the past two decades, but in a way that in retrospect may have caused as much harm as good. Since GCMs do not usually represent subgrid variability, cold dry downdraft air instantaneously mixes with the undisturbed moist humid boundary-layer air that generated the initial convection. This stabilizes the boundary later and suppresses further convection-might this be why GCMs have difficulty raining over land in late afternoon?

Qian et al. (1998) noted that downdraft air reaching the boundary layer actually remains distinct for hours and spreads, lifting undisturbed high moist static energy air at its edge and thus promoting further convection for hours, a point also emphasized by Tompkins (2001). Qian et al. developed a wake parameterization that accounted separately for the evolving properties of the downdraft cold pool. Grandpeix and Lafore (2010) use cold pool convergence to generate sufficient lifting energy to overcome convective inhibition. In an SCM, this delays triggering of the Emanuel deep convection scheme (which is normally initiated by positive convective available potential energy), producing a more realistic diurnal cycle (Rio et al. 2009). Mapes (2000) explored the competition between the stabilizing and destabilizing effects of downdrafts in a simple model of convectively coupled waves, asking, "Has a whole generation of cumulus parameterizations focused on the smaller of the two effects of downdrafts?"

The challenges of implementing a cold pool parameterization are the added prognostic variables (not to mention others associated with the resulting mesoscale updraft/downdraft) and one's conceptions about how cold pools organize convection. Mapes and Neale (2011) suggest a novel approach to the former challenge. They define a single abstract dimensionless prognostic variable org, which captures whatever physics of organization one wishes to include as a forcing term, opposed by a relaxation with specified decay time that eliminates organization when forcing ceases. At each time step, the current value of org is used to diagnose whatever subgrid variability one wishes to affect convection.

One such effect proposed by Mapes and Neale (2011) is that since downdrafts from prior convection spawn new convection in the vicinity of the old, the new events rise through more humid air than the gridbox mean due to detrainment, rain evaporation, and cloud edge mixing from the older event-a possible explanation for the Schumacher and Houze (2006) tropospheric humidity effect on sustainability. Figure 10 shows a snapshot of weakly organizing convection in a CRM (Del Genio et al. 2011b). The left panel shows a classification of the convective and stratiform rain areas and a transition region in which detrainment and downdrafts occur. The right panel shows the corresponding 600-mb relative humidity. Very humid air occupies a much larger area than the convection itself, reducing the efficacy of entrainment and promoting further deep development. The domain mean humidity is $28 \%$ drier than convective updraft air, but the transition region air that surrounds the convective updrafts is only $12 \%$ drier.

Another proposed effect of the cold pool convergence is on the entrainment rate itself. Khairoutdinov and Randall (2006) show that after the onset of cold pools, the convergence organizes convecting air at larger scales than that of boundary-layer turbulence (Fig. 11). If 


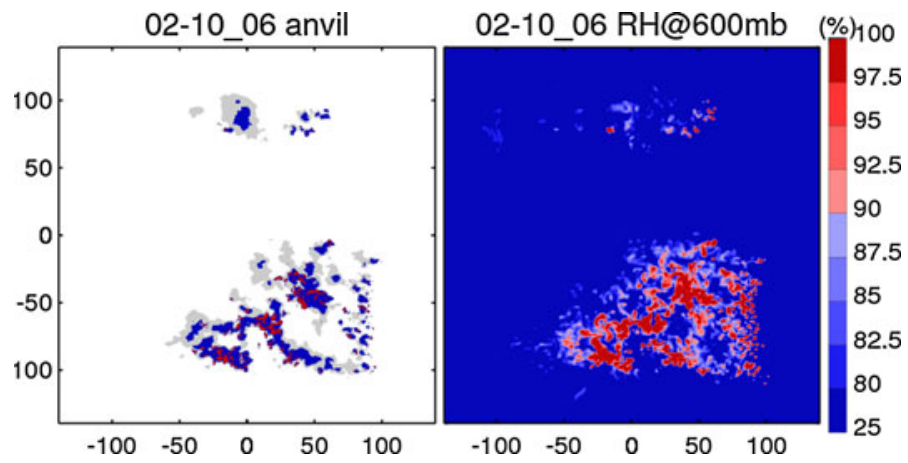

Fig. 10 Left instantaneous convective cluster cloud classification mask in the latitude-longitude plane in a CRM simulation centered on Darwin, Australia. Red deep convective updrafts. Blue transition region. Gray stratiform rain region. Right corresponding 600-mb relative humidity field. From Del Genio et al. (2011b)

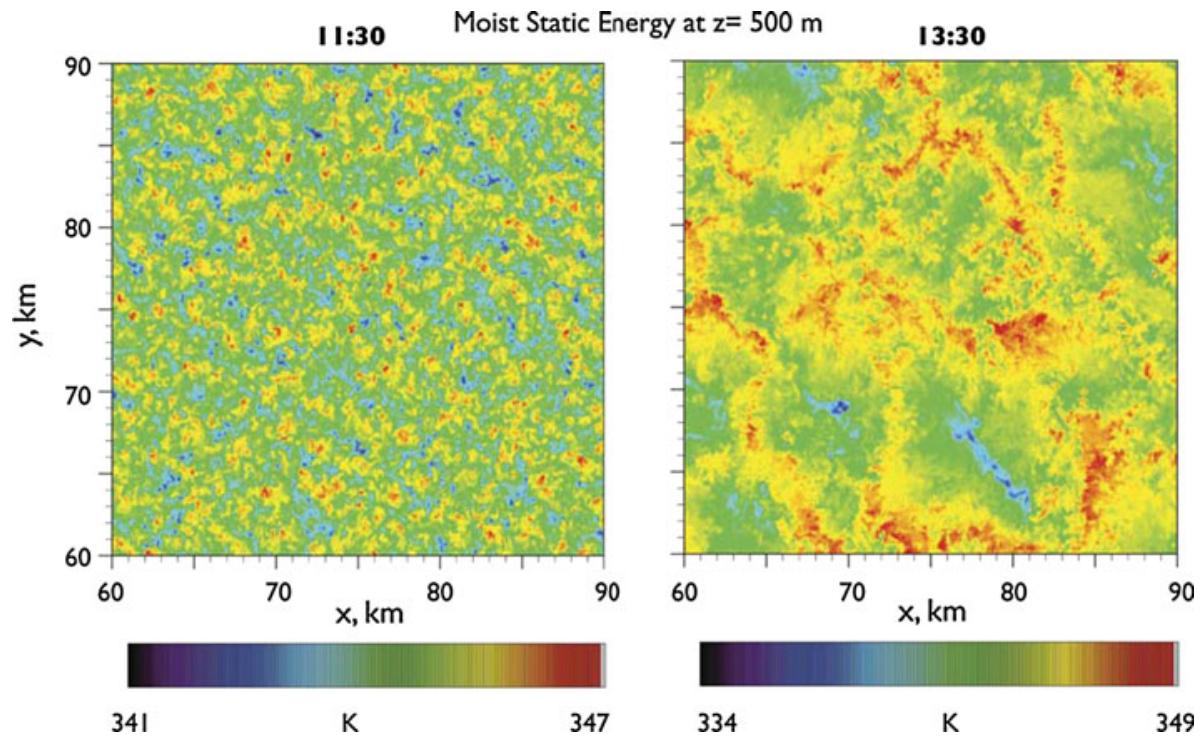

Fig. 11 Latitude-longitude moist static energy field at $500 \mathrm{~m}$ altitude at (left) 11:30 LST and (right) 13:30 LST, before and after the transition to deep convection respectively, in a CRM simulation of diurnal convective development over the Amazon. From Khairoutdinov and Randall (2006) () Copyright 2006 AMS)

entrainment varies inversely with parcel size, entrainment rates should thus decrease as convection deepens and cold pools form, perhaps explaining the CRM-inferred decrease in entrainment with convection depth noted earlier. Del Genio and Wu (2010) have a different take on this process, suggesting that within the conceptual framework of the Gregory (2001) entrainment parameterization the enhancement of cloud base vertical velocity by cold pool convergence is what weakens entrainment.

These effects might perpetuate convection long enough to improve the diurnal cycle of continental convection. To simulate the second baroclinic mode heating profile required by several theories of the MJO, however, will require a separate parameterization of the dynamics of mesoscale updrafts and downdrafts. The lifetime of the stratiform rain region 
depends on the time-varying balance between the convective detrainment condensate source and the sink due to sedimentation of ice within the stratiform area. To get the source right, one must parameterize the persistence of convection after onset, which depends on how long the cold pool remains a distinct entity. This operates differently over ocean and land (Del Genio et al. 2011b): ocean cold pools recover at a rate dictated by surface latent and sensible heat fluxes, while cold pools over land quickly cool the land surface and suppress surface fluxes, so the cold pool remains close to its initial temperature while the undisturbed boundary layer cools diurnally to a similar temperature. The sink depends on properly characterizing the dynamics and microphysics of the stratiform rain region itself. In this region, updraft speeds are smaller than ice fall speeds-just the opposite of the convective region-leading to slow deposition growth as particles sediment. The ice eventually melts and evaporates, forming the mesoscale downdraft (Biggerstaff and Houze 1991). Once convection ceases, these processes determine how long the upper-level heating continues. The stratiform/anvil cloud directly affects the planetary energy balance (Clement and Soden 2005; Del Genio et al. 2005) and potentially cloud feedback (Yao and Del Genio 1999; Zelinka and Hartmann 2010) because of its large area, though it has little effect on water vapor feedback since the condensate is a small fraction of the total detrained water (Del Genio et al. 1991).

One difficulty with parameterizing mesoscale organization is that as the resolution of GCMs increases the size of convective clusters begins to exceed that of the gridbox. Numerical weather prediction models now routinely run at resolutions of $10-20 \mathrm{~km}$, and even some climate models now have resolution finer than $100 \mathrm{~km}$. By itself, increasing resolution does not appear to improve the simulation of the rainfall diurnal phase until a model gets down to almost convection-permitting $(<10 \mathrm{~km})$ resolution (Dirmeyer et al. 2011), suggesting that uncertainties in parameterizing cloud-scale processes are still important. However, as resolution increases, we might anticipate that some of the missing mesoscale updraft and downdraft circulation and associated second baroclinic mode heating will be resolved by the GCM dynamics. The question then becomes how to seamlessly navigate this transition from parameterized to resolved heating and precipitation without double-counting. Perhaps the transition region of detrainment, downdrafts, and cold pools between the convective and stratiform rain regions of mesoscale clusters (blue area in Fig. 10) will need to be parameterized at intermediate (mesoscale) resolution, but with communication between neighboring gridboxes that allows the resolved circulation to capture the vertical motions of the stratiform rain region. Even for current conventional cumulus parameterizations that do not treat organization, the assumption that convective updrafts occupy a very small area of the gridbox begins to break down as resolution increases. A general framework for adapting conventional parameterizations to operate at intermediate resolutions has been suggested by Arakawa et al. (2011).

\section{Conclusions}

Our ability to simulate energy flows in the Earth system is unfortunately limited by transports by small-scale processes such as moist convection that are still parameterized in global climate models. Historically, cumulus parameterization has received attention primarily for its effect on the diabatic heating profile and the general circulation. Only in the past decade has it become clear that tropospheric humidity acts as the convection throttle that regulates (a) where clouds form, thus controlling the planetary energy balance, (b) how energy is removed from the surface to higher altitude, and (c) how temporal variability in 
weather and planetary-scale lateral energy transports occurs. Cumulus parameterizations are beginning to change to reflect this new view, but adequately portraying convection in all its realizations remains a difficult problem. Progress is slower than might be expected because of the small number of scientists actively involved in model development and the financial and career roadblocks associated with pursuing such research (Jakob 2010).

To date, metrics for model evaluation have focused almost exclusively on time mean two-dimensional spatial distributions of easily observed parameters. It has become clear that such metrics have no predictive value for climate feedbacks and climate sensitivity (e.g., Collins et al. 2011). They are also probably not helpful for assessing most other important features of future climate projections, because temporal variability gives greater insight into the physical processes at work. In addition, most of what matters about climate change for users of climate model projections concerns specific events or anomalous regional weather patterns rather than mean fields. For the IPCC AR4 models, there has been some success in using interannual (Bony and Dufresne 2005) and decadal (Clement et al. 2009) variability to differentiate the fidelity of models with positive and negative low cloud feedbacks. The fact that the AR4 model sensitivity spread can be attributed largely to low cloud feedbacks does not mean that other cloud types do not contribute to uncertainty in climate sensitivity, however. Rather, the similar high and convective cloud response to climate change among the AR4 models in the Bony and Dufresne (2005) study may be due to shortcomings all the models have in common and thus may underestimate the inherent feedback uncertainty. Given the insensitivity of these models to tropospheric humidity and their failure to simulate the MJO and diurnal cycle, the results of perturbed parameter ensembles (Sanderson et al. 2010) should be a caution to the climate community to devote as much attention to the simulation of high and convective clouds as is currently being devoted to understanding low clouds.

It seems unlikely that it will ever be possible to establish a general set of metrics that can be used to anoint one subset of models as our most reliable indicators of all aspects of climate change. A more fruitful strategy might identify a subset of the most important climate change issues (climate sensitivity, Arctic sea ice loss, extreme precipitation, subtropical continental drought, etc.) and define separate metrics for each one based on appropriate aspects of current temporal variability that are diagnostic of the processes that cause the specific change. Diagnostics that reveal the interaction between convection and tropospheric humidity should be a high priority in any such effort.

Acknowledgments This work was originally presented at the Workshop "Observing and Modeling Earth's Energy Flows" held at the International Space Science Institute, Bern, Switzerland, 10-14 January 2011. The research described here was supported by the DOE Atmospheric System Research Program, the NASA Modeling and Analysis Program, the NASA Precipitation Measurement Missions, and the NASA CloudSat/CALIPSO Mission. I thank the anonymous reviewers for constructive comments that strengthened the paper.

Open Access This article is distributed under the terms of the Creative Commons Attribution Noncommercial License which permits any noncommercial use, distribution, and reproduction in any medium, provided the original author(s) and source are credited.

\section{References}

Arakawa A, Schubert WH (1974) Interaction of a cumulus cloud ensemble with the large-scale environment. Part I. Theoretical formulation and sensitivity tests. J Atmos Sci 31:674-701 
Arakawa A, Jung J-H, Wu C-M (2011) Toward unification of the multiscale modeling of the atmosphere. Atmos Chem Phys 11:3731-3742

Benedict JJ, Randall DA (2007) Observed characteristics of the MJO relative to maximum rainfall. J Atmos Sci 64:2332-2354

Biggerstaff MI, Houze RA Jr (1991) Kinematic and precipitation structure of the 10-11 June 1985 squall line. Mon Weather Rev 119:3034-3065

Bladé I, Hartmann DL (1993) Tropical intraseasonal oscillations in a simple nonlinear model. J Atmos Sci 50:2922-2939

Bony S, Dufresne J-L (2005) Marine boundary layer clouds at the heart of tropical cloud feedback uncertainties in climate models. Geophys Res Lett 32:L20806. doi:10.1029/2005GL023851

Bretherton CS, Peters ME, Back LE (2004) Relationships between water vapor path and precipitation over the tropical oceans. J Clim 17:1517-1528

Chen Y, Del Genio AD (2009) Evaluation of tropical cloud regimes in observations and a general circulation model. Clim Dyn 32:355-369

Clement AC, Soden B (2005) The sensitivity of the tropical-mean radiation budget. J Clim 18:3189-3203

Clement A, Burgman R, Norris J (2009) Observational and model evidence for positive low-level cloud feedback. Science 325:460-464

Collins M, Booth BBB, Bhaskaran B, Harris GR, Murphy JM, Sexton DMH, Webb MJ (2011) Climate model errors, feedbacks and forcings: a comparison of perturbed physics and multi-model ensembles. Clim Dyn 36:1737-1766

Dai A (2006) Precipitation characteristics in eighteen coupled climate models. J Clim 19:4605-4630

Del Genio AD, Wu J (2010) Entrainment and the diurnal cycle of continental convection. J Clim 23:2722-2738

Del Genio AD, Lacis AA, Ruedy RA (1991) Simulations of the effect of a warmer climate on atmospheric humidity. Nature 351:382-385

Del Genio AD, Kovari W, Yao M-S, Jonas J (2005) Cumulus microphysics and climate sensitivity. J Clim 18:2376-2387

Del Genio AD, Yao M-S, Jonas J (2007) Will moist convection be stronger in a warmer climate? Geophys Res Lett 34:L16703. doi:10.1029/2007GL030525

Del Genio AD, Chen Y, Kim D, Yao M-S (2011a) The MJO transition from shallow to deep convection in CloudSat/CALIPSO data and GISS GCM simulations. J Clim (in revision)

Del Genio AD, Wu J, Chen Y (2011b) Characteristics of mesoscale organization in WRF simulations of convection during TWP-ICE. J Clim (submitted)

Derbyshire SH, Beau I, Bechtold P, Grandpeix J-Y, Piriou J-M, Redelsperger J-L, Soares PMM (2004) Sensitivity of moist convection to environmental humidity. Q J R Meteorol Soc 130:3055-3079

Dirmeyer PA et al (2011) Simulating the diurnal cycle of rainfall in global climate models: resolution versus parameterization. Clim Dyn (in press). doi:10.1007/s00382-011-1127-9

Donner LJ (1993) A cumulus parameterization including mass fluxes, vertical momentum dynamics, and mesoscale effects. J Atmos Sci 50:889-906

Emanuel KA (1991) A scheme for representing cumulus convection in large-scale models. J Atmos Sci 48:2313-2335

Emanuel KA, Neelin JD, Bretherton CS (1994) On large-scale circulations in convecting atmospheres. Q J R Meteorol Soc 120:1111-1143

Fasullo JT (2010) Robust land-ocean contrasts in energy and water cycle feedbacks. J Clim 23:4677-4693

Futyan JM, Del Genio AD (2007) Deep convective system evolution over Africa and the tropical Atlantic. J Clim 20:5041-5060

Grabowski WW et al (2006) Daytime convective development over land: a model intercomparison based on LBA observations. Q J R Meteorol Soc 132:317-334

Grandpeix J-Y, Lafore J-P (2010) A density current parameterization coupled with Emanuel's convection scheme. Part I: the models. J Atmos Sci 67:881-897

Grant ALM, Brown AR (1999) A similarity hypothesis for shallow-cumulus transports. Q J R Meteorol Soc 125:1913-1936

Gregory D (2001) Estimation of entrainment rate in simple models of convective clouds. Q J R Meteorol Soc 127:53-72

Gregory D, Rowntree PR (1990) A mass flux convection scheme with representation of cloud ensemble characteristics and stability-dependent closure. Mon Weather Rev 118:1483-1506

Guichard F et al (2004) Modeling the diurnal cycle of deep precipitating convection over land with cloudresolving models and single-column models. Q J R Meteorol Soc 130:3139-3172

Hack JJ (1994) Parameterization of moist convection in the National Center for Atmospheric Research community climate model (CCM2). J Geophys Res 99:5551-5568 
Hannah WM, Maloney ED (2011) The role of moisture-convection feedbacks in simulating the MaddenJulian Oscillation. J Clim 24:2754-2770

Heus T, van Dijk G, Jonker HJJ, Van den Akker HEA (2008) Mixing in shallow cumulus clouds studied by Lagrangian tracking. J Atmos Sci 65:2581-2597

Hirose M, Oki R, Shimizu S, Kacji M, Higashiuwatoko T (2008) Finescale diurnal rainfall statistics refined from eight years of TRMM PR data. J Appl Meteorol Clim 47:544-561

Holloway CE, Neelin JD (2009) Moisture vertical structure, column water vapor, and tropical deep convection. J Atmos Sci 66:1665-1683

Houze RA Jr (2004) Mesoscale convective systems. Rev Geophys 42:RG4003. doi:10.1029/2004RG000150

$\mathrm{Hu}$ Q, Randall DA (1994) Low-frequency oscillations in radiative-convective systems. J Atmos Sci 51:1089-1099

Jakob C (2010) Accelerating progress in global atmospheric model development through improved parameterizations-challenges, opportunities and strategies. Bull Am Meteorol Soc 91:869-875

Jakob C, Siebesma AP (2003) A new subcloud model for mass-flux convection schemes: influence on triggering, updraft properties, and model climate. Mon Weather Rev 131:2765-2778

Jensen MP, Del Genio AD (2006) Factors limiting convective cloud-top height at the ARM Nauru Island climate research facility. J Clim 19:2105-2117

Kemball-Cook SR, Weare BC (2001) The onset of convection in the Madden-Julian oscillation. J Clim 14:780-793

Khairoutdinov M, Randall D (2006) High-resolution simulation of shallow-to-deep convection transition over land. J Atmos Sci 63:3421-3436

Khouider B, Majda AJ (2006) A simple multicloud parameterization for convectively coupled tropical waves. Part I: linear analysis. J Atmos Sci 63:1308-1323

Kiladis GN, Straub KH, Haertel PT (2005) Zonal and vertical structure of the Madden-Julian Oscillation. J Atmos Sci 62:2790-2809

Kim D et al (2009) Application of MJO simulation diagnostics to climate models. J Clim 22:6413-6436

Kim D, Sobel AH, Del Genio AD, Chen Y, Camargo SJ, Yao M-S, Kelley M, Nazarenko L (2011a) The tropical subseasonal variability simulated in the NASA GISS general circulation model. J Clim (submitted)

Kim D, Sobel AH, Maloney ED, Frierson DMW, Kang I-S (2011b) A systematic relationship between intraseasonal variability and mean state bias in AGCM simulations. $J$ Clim. doi: 10.1175/2011JCLI4177.1

Kuang Z (2008) A moisture-stratiform instability for convectively coupled waves. J Atmos Sci 65:834-854

Kuang Z, Bretherton CS (2006) A mass-flux scheme view of a high-resolution simulation of a transition from shallow to deep cumulus convection. J Atmos Sci 63:1895-1909

Lin J-L et al (2006) Tropical intraseasonal variability in 14 IPCC AR4 climate models. Part I: convective signals. J Clim 19:2665-2690

Madden R, Julian P (1971) Detection of a 40-50 day oscillation in the zonal wind in the tropical Pacific. J Atmos Sci 28:702-708

Mapes BE (2000) Convective inhibition, subgrid-scale triggering energy, and stratiform instability in a toy tropical wave model. J Atmos Sci 57:1515-1535

Mapes BE, Neale RB (2011) Parameterizing convective organization to avoid the entrainment dilemma. J Adv Model Earth Syst 3:M06004. doi:10.1029/2011MS000042

Mapes BE, Tulich S, Lin J, Zuidema P (2006) The mesoscale convection life cycle: building block or prototype for large-scale tropical waves? Dyn Atmos Ocean 42:3-29

Moorthi S, Suarez MJ (1992) Relaxed Arakawa-Schubert: a parameterization of moist convection for general circulation models. Mon Weather Rev 120:978-1002

Morita J, Takayabu YN, Shige S, Kodama Y (2006) Analysis of rainfall characteristics of the MaddenJulian Oscillation using TRMM satellite data. Dyn Atmos Ocean 42:107-126

Neale RB, Richter JH, Jochum M (2008) The impact of convection on ENSO: from a delayed oscillator to a series of events. J Clim 21:5904-5924

Neggers RAJ, Siebesma AP, Jonker HJJ (2002) A multiparcel model for shallow cumulus convection. J Atmos Sci 59:1655-1668

Paluch IR (1979) The entrainment mechanism in Colorado cumuli. J Atmos Sci 36:2467-2478

Qian L, Young GS, Frank WM (1998) A convective wake parameterization scheme for use in general circulation models. Mon Weather Rev 126:456-469

Raymond DJ, Sessions SL, Sobel AH, Fuchs Z (2009) The mechanics of gross moist stability. J Adv Model Earth Syst 1. doi:10.3894/JAMES.2009.1.9

Riehl H, Malkus JS (1958) On the heat balance in the equatorial trough zone. Geophysica 6:503-538 
Rio C, Hourdin F, Grandpeix J-Y, Lafore J-P (2009) Shifting the diurnal cycle of parameterized deep convection over land. Geophys Res Lett 36:L07809. doi:10.1029/2008GL036779

Romps DM, Kuang Z (2010a) Do undiluted convective plumes exist in the upper tropical troposphere? J Atmos Sci 67:468-484

Romps DM, Kuang Z (2010b) Nature vs. nurture in shallow convection. J Atmos Sci 67:1655-1666

Sanderson BM, Shell KM, Ingram W (2010) Climate feedbacks determined using radiative kernels in a multi-thousand member ensemble of AOGCMs. Clim Dyn 30:175-190

Schumacher C, Houze RA Jr (2006) Stratiform precipitation production over sub-Saharan Africa and the tropical East Atlantic as observed by TRMM. Q J R Meteorol Soc 132:2235-2255

Siebesma AP et al (2003) A large eddy simulation intercomparison study of shallow cumulus convection. J Atmos Sci 60:1201-1219

Stephens GL, Webster PJ, Johnson RH, Engelen R, L'Ecuyer T (2004) Observational evidence for the mutual regulation of the tropical hydrological cycle and tropical sea surface temperatures. J Clim $17: 2213-2224$

Thayer-Calder K, Randall DA (2009) The role of convective moistening in the Madden-Julian Oscillation. J Atmos Sci 66:3297-3312

Tokioka T, Yamazaki K, Kitoh A, Ose T (1988) The equatorial 30-60 day oscillation and the ArakawaSchubert penetrative cumulus parameterization. J Meteorol Soc Jpn 66:883-901

Tompkins AM (2001) Organization of tropical convection in low vertical wind shears: the role of cold pools. J Atmos Sci 58:1650-1672

Trenberth KE, Fasullo JT (2010) Simulation of present-day and twenty-first-century energy budgets of the southern oceans. J Clim 23:440-454

Trenberth KE, Fasullo JT, Kiehl J (2009) Earth's global energy budget. Bull Am Meteorol Soc 90:311-323

Tromeur E, Rossow WB (2010) Interaction of tropical deep convection with the large-scale circulation in the MJO. J Clim 23:1837-1853

Warner J (1970) On steady-state one-dimensional models of cumulus convection. J Atmos Sci 27:1035-1040

Weickmann KM, Lussky GR, Kutzbach JE (1985) Intraseasonal (30-60 day) fluctuations of outgoing longwave radiation and $250 \mathrm{mb}$ streamfunction during northern winter. Mon Weather Rev 113:941-961

Wheeler M, Kiladis GN (1999) Convectively coupled equatorial waves: analysis of clouds and temperature in the wavenumber-frequency domain. J Atmos Sci 56:374-399

Yao M-S, Del Genio AD (1999) Effects of cloud parameterization on climate changes in the GISS GCM. J Clim 12:761-779

Yuter SE, Houze RA Jr (1998) The natural variability of precipitating clouds over the western Pacific warm pool. Q J R Meteorol Soc 124:53-99

Zelinka MD, Hartmann DL (2010) Why is longwave cloud feedback positive? J Geophys Res 115:D16117. doi:10.1029/2010JD013817

Zhang Y, Klein SA (2010) Mechanisms affecting the transition from shallow to deep convection over land: inferences from observations of the diurnal cycle collected at the ARM Southern Great Plains site. J Atmos Sci 67:2943-2959

Zhang GJ, McFarlane NA (1995) Sensitivity of climate simulations to the parameterization of cumulus convection in the Canadian Climate Centre general circulation model. Atmos Ocean 33:407-446 